\title{
Menakar Peran dan Tantangan Pemerintah Daerah Dalam Perlindungan Hukum Pada Pekerja Migran Indonesia, Sebuah Studi di Kabupaten Bangkalan Madura
}

\author{
Devi Rahayu, Susilah Ningwahyu, Nunuk Nuswardani, Boedi Mustiko \\ Fakultas Hukum, Universitas Trunojoyo Madura \\ rahayudevi78@yahoo.com
}

Submit: 11-09-2019; Review: 16-12-2020; Terbit: 16-12-2020

\begin{abstract}
Migration is carried out by Indonesia migrant workers (PMI) because of the lack of employment in the village and low wages. Getting a better economic life is the reason of migration. The PMI migration process has never been separated from the problems that have occurred sence the pre-placement process, durung work and after placement. There are cases of PMI's death penalty from bangkalan, namely siti zaenab and zainal misli as well as the issue of deportation. This article focus on the implementation of protection and the efforts made by the Bangkalan regency government. The research method used is empirical by using a fact and case approach. Data analysis was carried out qualitatively and than described descriptively. There are 3 forms of protection for Indonesian migrant workers, namely protection before work by providing counseling, during work by coordinating with related institutions and after working by conducting job training. Efforts were made to issue deportation by preventing PMI from leaving non procedurally, for cases of death at work and capital punishment carried out in coordinating with LP3TKI Surabaya.
\end{abstract}

Keywords: Migrant Workers, Protection, Bangkalan.

\begin{abstract}
Abstrak
Migrasi dilakukan pekerja migran Indonesia (PMI) karena minimnya lapangan pekerja di desa dan upah yang rendah, sementara untuk jenis pekerjan yang sama di luar negeri mendapatkan upah yang lebih tinggi. Mendapatkan kehidupan ekonomi yang lebih baik menjadi alasan melakukan migrasi. Proses migrasi PMI tak pernah lepas dari permasalahan yang terjadi sejak proses pra penempatan, saat bekerja dan purna penempatan. Terdapat kasus hukuman mati PMI asal Bangkalan, yaitu Siti Zaenab dan Zainal Misli serta persoalan deportasi. Penulisan ini berfokus pada pelaksanaan perlindungan pekerja migran Indonesia di Kabupaten Bangkalan dan upaya yang di lakukan oleh pemerintah Kabupaten Bangkalan terhadap kasus-kasus yang menimpa pekerja migran. Metode penelitian yang digunakan adalah empiris dengan menggunakan pendekatan fakta dan kasus. Sedangkan pengumpulan data
\end{abstract}


dilakukan dengan cara wawancara dan studi kepustakaan. Analisis data dilakukan secara kualitatif dan kemudian dijelaskan secara dekriptif. Pelaksanaan perlindungan pekerja migran Indonesia di Kabupaten Bangkalan terdapat 3 bentuk yaitu perlindungan sebelum bekerja dengan melakukan penyuluhan, selama bekerja dengan meakukan koordinasi dengan instansi terkait, dan sesudah bekerja dengan melakukan pelatihan kerja. Upaya yang dilakukan persoalan deportasi dengan mencegah PMI berangkat secara non procedural, terhadap kasus-kasus meninggal ditempat kerja dan hukuman mati dilakukan dengan berkoordinasi dengan LP3TKI Surabaya.

\section{Kata Kunci: Pekerja Migran, Perlindungan, Bangkalan.}

\section{Pendahuluan}

Dari tahun 2015 sampai 2016 banyak masyarakat Indonesia yang berpergian ke luar negeri (Yanite Patriela, diakses pada 1 Oktober 2019), namun sebagian besar mereka pergi kesana untuk bekerja dalam sektor informal. Hal ini terjadi karena latar belakang pendidikan, status dan ekonomi.(Riris Ardhanariswari, 2017: 38). Bekerjanya orang Indonesia di luar wilayah Republik Indonesia dalam sektor informal biasanya di sebut Tenaga Kerja Indonesia (selanjutnya disebut TKI). TKI adalah sebutan bagi warga negara Indonesia yang bekerja diluar negeri dalam hubungan kerja untuk jangka waktu tertentu dengan menerima upah. Alasan besaran upah yang lebih besar dengan negara asal atas pekerjaan yang sejenis menjadikan salah satu alasan bekerja ke luar negeri.(Tri Listiani, 2012: 313) Masalah ketenagakerjaan merupakan bagian yang tak dapat dipisahkan dari permasalahan ekonomi, sehingga perencanaan ekonomi juga berkait dengan perencanaan ketenagakerjaan. (Dwi Nofita, 2019:1955).

Dengan disahkannya UndangUndang Nomor 18 Tahun 2017 tentang Pelaksanaan Perlindungan Pekerja Migran Indonesia (selanjutnya disebut UU PPMI), istilah TKI berganti menjadi Pekerja Migran Indonesia. Menurut UU PPMI, bahwa Pekerja Migran Indonesia adalah setiap warga negara Indonesia yang akan, sedang, atau telah melakukan pekerjaan dengan menerima upah di luar wilayah Republik Indonesia. 
Di Indonesia istilah pekerja sama dengan buruh/pekerja kasar. Lalu Husni menyebutkan bahwa buruh/pekerja yaitu pekerja Indonesia yang melakukan pekerjaan kasar untuk menerima upah seperti kuli, tukang, mandor, dan pembantu rumah tangga (Lalu Husni, 2012: 43). Sedangkan menurut Koesparmono Irsan dan Armansyah pekerja/buruh adalah potensi yang sudah terikat hubungan pekerjaan dengan pengusaha yang kemudian nantinya menerima imbalan dalam bentuk uang (Koesparmono, 2016: 27). Kegiatan Penempatan TKI yaitu kegiatan untuk mempertemukan TKI dengan pemberi kerja di negara penempatan yang sesuai dengan bakat, minat, dan kemampuannya dengan beberapa proses tertentu (Musan Abdurrahma, 2006: 34).

Pekerja migran dari tahun 2010 sampai tahun 2015 mengalami peningkatan. Menurut negara penempatan dari tahun 2010 sampai 2015 jumlah tenaga kerja Indonesia sudah mencapai 3.686 orang yang tersebar di Asean (Malaysia, Singapura, Brunei Darussalam, dan lainnya), Asia selain ASEAN (Hong Kong SAR, Taiwan Provinsi China, Korea Selatan, Jepang Makau, dan lainnya), Australia dan Oseania (Australia dan lainnya), Timur Tengah (Arab Saudi, UEA, Kuwait, Bahrain, Qatar, Oman, Yordania, Mesir, Siprus, Sudan, dan lainnya), Afrika (Afrika Selatan dan lainnya), Amerika, Eropa (Belanda, Italia, Jerman, Inggris, Perancis, Spanyol, dan lainnya).(bank Indonesia dan BNP2TKI, diakses pada 11 Sepember 2018) Badan Nasional Penempatan dan Perlindungan Tenaga Kerja Indonesia (BNP2TKI) menyebutkan dalam periode Januari sampai April 2018, sebanyak 87 ribu Pekerja Migran Indonesia yang berangkat mengadu nasib ke luar negeri. Dan sebanyak 61 persen Pekerja Migran adalah perempuan (BNP2TKI, diakses 23 September 2018).

Peningkatan jumlah pekerja migran itu disebabkan karena peningkatan jumlah penduduk yang tiap tahunnya bertambah dan tidak diimbangi oleh pembangunan yang merata sehingga terjadi kesenjangan 
sosial ekonomi dan mempengaruhi penduduk untuk mencari daerah atau melakukan migrasi yang menyediakan kebutuhannya dan mengakibatkan distribusi penduduk yang tidak merata. Setiap individu memiliki bermacam kebutuhan seperti kebutuhan ekonomi, budaya, social dan psikologis. Bila kebutuhan tersebut tidak terpenuhi di tempat tinggalnya, hal ini menimbulkan tekanan yang mendorong keinginan untuk dapat dipenuhi walau di harus ke tempat lain (Aga Natalis, 2018: 110). Everet Lee pada tahun 1966 menyampaikan bahwa teori migrasi internasional sangat mempengaruhi seseorang untuk bermigrasi antar negara yaitu (Ridwan Wahyudi, diakses 30 September, 2018) : a). Pertimbangan gaji yang rendah di negara asal, b) Terbatasnya lapangan pekerjaan, c) Rendahnya akses sosial masyarakat di negara asal, d) Gaji yang tinggi di negara penempatan, e) Sedikitnya angka pengangguran di negara penempatan, f) Kebiasaan seseorang untuk merantau.

Setelah Everet Lee menyampaikan teori migrasi tersebut pada perkembangan selanjutnya bermunculan beberapa teori mengenai migrasi internasional : (1) Douglas S. Massey et al tahun 1993 menyampaikan teori Neoclassical Economy. Penyebab utama migrasi menurut pendekatan makro yaitu : Gaji yang berbeda antara negara asal dan negara penempatan. Mekanisme pasar kerja juga akan mempengaruhi migrasi internasional. Migrasi internasional pekerja ini dikontrol oleh pemerintah melalui peraturan pasar kerja, baik dari negara asal maupun negara penempatan. Kebutuhan akan tenaga kerja terlatih dan berpendidikan dipenuhi oleh negara maju, sedngakan kebutuhan tenaga kerja yang tidak terlatih dipenuhi oleh negara berkembang.(Rizky Dian, 2018: 166) Hal ini pulalah yang menjadikan alasan sector informal yang banyak ditawarkan negara tujuan pekerja migran.

Selain itu terdapat pendekatan mikro berasumsi bahwa pendapatan yang besar bisa didapatkan di negara penempatan daripada di negara asal. Bahwa dengan melakukan migrasi 
internasional, pekerja migran akan mendapatkan keuntungan yang lebih besar karena pendapatan yang diterima di negara penempatan lebih besar daripada negara asalnya. (2) Stark dan Boom tahun 1985 menyampaikan teori New Economic of Migration bahwa seseorang bermigrasi bukan dipengaruhi karena perbedaan upah. Oleh karenanya migrasi internasional akan terus dilakukan meskipun upah yang didapatkan berbeda. (3) Castles dan Miller pada tahun 2009 menyampaikan teori Segmentation of Labour market yaitu permintaan migrasi internasional pekerja yang besar oleh majikan di negara penempatan. Jadi majikan di negara penempatan banyak yang membutuhkan pekerja Indonesia. Teori Historical-structural Theory dikemukakan oleh Castels dan Miller tahun 2009 yaitu perbedaan pembagian kuasa ekonomi dan politik dalam ekonomi dunia menyebabkan migrasi internasional.

Dari pemahaman teori-teori migrasi tersebut jika dikembalikan pada konteks Indonesia maka yang cocok dengan keadaan Indonesia yaitu teori migrasi yang disampaikan oleh Everet Lee. Pekerja Indonesia melakukan migrasi karena di Indonesia untuk jenis pekerjaan yang sama mendapatkan gaji yang rendah jika dibandingkan dengan di luar negeri. Tidak hanya gaji yang rendah, pekerja Indonesia melakukan migrasi karena di Indonesia sendiri masih minim lapangan pekerja sehingga pekerja Indonesia melakukan migrasi karena banyaknya kesempatan kerja dan kecenderungan pekerja Indonesia untuk melakukan migrasi. Selain factor ekonomi terdapat beberapa factor lain yang mem[epengaruhi seseorang melakukan migrasi yaitu factor social, fisik, demograsi dan kultural. Dalam hal ini migrasi tidak hanya dipandang sebagai persoalan teknis tapi berhubungan dengan konteks politik sebuah Negara (Aga Natalis, 2018: 110). Proses migrasi internasional tidak bisa dibatasi karena memang pada hakikatnya bekerja merupakan hak dasar manusia sesuai dengan ketentuan Pasal 27 Ayat (2) Undang-Undang Dasar Negara 
Republik Indonesia 1945, yaitu tiaptiap warga negara berhak atas pekerjaan dan penghidupan yang layak bagi kemanusiaan. Sebagai warga negara pekerja migran membutuhkan jaminan perlindungan dari negara, baik yang dilakukan oleh pemerintah pusat maupun daerah (Bambang Widiyahseno, 2018: 502).

Keberadaan pekerja migran Indonesia bagi pemerintah Indonesia dan masyarakat membawa hal positif dan hal negatif. Hal positif bagi Indonesia yaitu pekerja migran dapat memperoleh pekerjaan sehingga bisa menghidupi keluarganya. Selain mendapat pekerjaan, keberadaan pekerja migran juga menambah devisa negara berupa mata uang asing yang diperoleh dari orang Indonesia yang kerja di luar negeri. Pada kenyataannya proses penempatan pekerja migran itu tidak hanya berdampak positif bagi keluarga maupun negara namun juga ada persoalan-persoalan yang muncul dalam proses migrasi mulai dari pra penempatan, saat bekerja dan purna penempatan (A Ramdlany, 2016: 227).
Permasalahan banyak terjadi pada saat pekerja migran bekerja di negara tujuan, seperti adanya gaji yang tidak dibayar, pekerjaan tidak sesuai perjanjian kerja, putus hubungan komunikasi, penyiksaan, kekerasan seksual, dan pembunuhan. Salah satu kasus yang menjadi ancaman bagi pekerja migran Indonesia yang bekerja di Malaysia dan Saudi Arabia adalah kasus kekerasan yang mengakibatkan hilangnya nyawa orang lain khususnya di Saudi Arabia, sehingga karena sistem hukum di Saudi Arabia menerapkan sistem hukum islam, maka ketika ada orang yang menghilangkan nyawa orang lain maka hukuman yang diberikan adalah hukuman mati. Setidaknya terdapat 300 PMI terancam hukuman mati.( Tyas Retno, 2017: 155). Sementara pada kasusu di Mlaysia sebagian besar PMI adalah pekerja kelas bawah dan mengalami diskriminasi (Noor Shaker, 2017: 20).

Hukuman mati juga terjadi dari beberapa pekerja migran asal Madura terutama dari Bangkalan. Seperti kasus Siti Zaenab, pekerja migran asal Desa 
Martajasah Kecamatan Bangkalan yang dihukum pancung di Arab Saudi karena dituduh membunuh majikan perempuannya pada tahun 1999 dan eksekusi mati dilaksanakan pada 14 April 2015. Setelah kasus Siti Zaenab, kemudian ada lagi kasus pekerja migran asal Bangkalan yang dihukum pancung yaitu Zaini Misrin, pekerja migran asal Desa Kebun Kecamatan Kamal Bangkalan yang dihukum pancung di Arab Saudi karena dituduh membunuh majikannya pada tahun 2004 dan eksekusi mati dilaksanakan pada 18 Maret 2018.

Kasus-kasus yang menimpa pekerja migran ini merupakan tanggung jawab negara. Tanggung jawab merupakan kondisi yang wajib menanggung segala sesuatu (jika terjadi sesuatu dapat digugat dan disalahkan) (Devi Rahayu, 2020:719). Dalam ketentuan UU PPMI terkait konteks tanggung jawab perlindungan sudah dirinci adanya tanggung jawab yang dilakukan oleh pemerintah pusat, provinsi, maupun daerah. Sedangkan kewajiban bagi pemerintah daerah berdasarkan ketentuan tersebut diatur dalam Pasal 41 UU PPMI, diantaranya melakukan ssialisasi, membuat basis data, memberikan perlindungan, membentuk layanan terpadu satu atap dan lain sebagainya:

Dalam hal ini pemerintah daerah diminta berperan besar dalam hal perlindungan. Perlindungan pekerja migran Indonesia menurut UU PPMI adalah segala upaya untuk melindungi kepentingan calon pekerja migran dan/pekerja migran Indonesia dan keluarganya dalam mewujudkan terjaminnya pemenuhan haknya dalam keseluruhan kegiatan sebelum bekerja, selama bekerja, dan setelah bekerja dalam aspek hukum, ekonomi, dan sosial. Perlindungan yang di maksud adalah upaya untuk menjamin pemenuhan hak-hak dari calon tenaga kerja baik dari sebelum penempatan, selama penempatan, dan sesudah penempatan.

Dalam pasal 2 UU PPMI dijelaskan bahwa perlindungan calon pekerja migran/pekerja migran Indonesia berasaskan keterpaduan, persamaan hak, pengakuan atas martabat dan hak asasi manusia, 
demokrasi, keadilan sosial, kesetaraan dan keadilan gender, non diskriminasi, anti perdagangan manusia, transparansi, akuntabilitas, dan berkelanjutan. Tujuan dilakukannya perlindungan calon pekerja migran Indonesia atau pekerja migran Indonesia yaitu (Joni Bambang, 2013: 257) : a). Memberdayakan dan mendayagunakan tenaga kerja secara optimal dan manusiawi, b). Menjamin dan melindungi calon pekerja migran/pekerja migran sejak didalam negeri, di negara tujuan, sampai kembali ke tempat asal di Indonesia, c). Meningkatkan kesejahteraan pekerja migran dan keluarganya.

Atas dasar hal tersebut, sudah terdapat regulasi yang mengatur mengenai perlindungan atas pekerja migran tetapi faktanya masih terdapat kasus-kasus yang terjadi sehingga perlu dikaji pelaksanaan perlindungan terhadap pekerja migran serta upaya yang dilakukan pemerintah daerah Bangkalan.

\section{Metode Penelitian}

Penelitian ini menggunakan metode hukum empiris, adapun yang dimaksud metode penelitian hukum empiris merupakan suatu fenomena hukum yang terjadi di kalangan masyarakat atau fakta sosial (Bahder Nasution, 2016: 124). Alasan menggunakan penelitian empiris pada penelitian ini adalah karena untuk mengetahui secara langsung tentang bagaimana perlindungan pekerja migran. Pendekatan penelitian ini menggunakan pendekatan fakta yang didasarkan pada fakta sosial atau melihat suatu kenyataan penerapan hukum dalam masyarakat dengan memperhatikan aspek hukum dan interaksi sosial masyarakat,sehingga berfungsi sebagai penunjang keperluan penelitian atau penulisan hukum (Ronni Hannitijo, 1998: 10). Sumber data primer didapat dari hasil wawancara dengna dinas terkait dan pekerja migran serta anggota keluarganya. Data sekunder didapat denga melakukan studi kepustakaan. Teknik analisis pada awalnya menggunakan analisis deskriptif, dengan mengelompokkan informasi dan data yang sama menurut sub aspek sehingga mempermudah dalam 
melakukan interpretasi. Setelah dikelompokkan menurut sub aspeknya maka selanjutnya analisis data yang digunakan adalah pendekatan kualitatif terhadap data primer dan data sekunder.

\section{Hasil dan Pembahasan}

Pelaksanaan Perlindungan Pekerja Migran Di Kabupaten Bangkalan

Setiap orang berhak mendapatkan perlindungan atas keamanan dan keselamatan. Menurut WJS. Poerwodarminto, perlindungan adalah tempat untuk orang-orang berlindung (Aries Haranto, 2016: 224). Menurut Suliati Rachmat, sejarah hukum perburuhan adalah pula sejarah perlindungan buruh, sebagai pihak yang sosial ekonomi lemah terhadap majikan yang lebih kuat. Suatu perlindungan yang bermula dengan keselamatan kerja, dan kemudian dengan perlindungan sosial, serta pada pertumbuhannya lebih lanjut melahirkan perlindungan hubungan kerja secara luas (Suliati : 332). Sedangkan perlindungan hukum terhadap tenaga kerja menurut Soepomo yakni penjagaan agar tenaga kerja dapat melakukan pekerjaan yang layak bagi kemanusiaan (Joni Bambang, 2013: 263).

Setiap pekerja migran Indonesia yang bekerja keluar negeri berhak mendapatkan perlindungan. Perlindungan yang didapat bisa dari pemerintah pusat maupun pemerintah daerah sesuai dengan ketentuan UU PPMI. Namun dalam hal ini pemerintah daerah diminta berperan besar dalam hal perlindungan. Perlindungan yang didapat oleh calon pekerja migran Indonesia atau pekerja migran Indonesia meliputi perlindungan sebelum bekerja, perlindungan selama bekerja, dan perlindungan setelah bekerja sesuai dengan ketentuan pasal 7 UU PPMI.

Dengan adanya perlindungan yang diberikan kepada pekerja migran Indonesia tersebut sebagai upaya untuk mensejahterakan pekerja migran Indonesia. Berikut merupakan realitas bentuk perlindungan sebelum bekerja, selama bekerja, dan setelah bekerja yang diberikan oleh Dinas 
Perindustrian dan Tenaga Kerja administratif sebelum pekerja migran Kabupaten Bangkalan kepada pekerja Indonesia asal Kabupaten Bangkalan migran Indonesia yang berasal dari bekerja ke luar negeri yaitu di Dinas Kabupaten Bangkalan

a) Perlindungan sebelum bekerja

Perlindungan sebelum bekerja merupakan bentuk perlindungan yang diberikan pemerintah Kabupaten Bangkalan melalui Dinas Perindustrian dan Tenaga Kerja Kabupaten Bangkalan kepada pekerja migran Indonesia asal Kabupaten Bangkalan yang akan berangkat bekerja ke luar negeri. Perlindungan sebelum bekerja diberikan kepada pekerja migran Indonesia asal Kabupaten Bangkalan dengan tujuan supaya pekerja migran Indonesia asal Kabupaten Bangkalan tidak mendapatkan masalah saat bekerja keluar negeri. Perlindungan sebelum bekerja diatur dalam pasal 8 ayat (1) UU PPMI yang meliputi :

Perlindungan administratif menurut pasal 8 ayat (2) UU PPMI meliputi kelengkapan dan keabsahan dokumen penempatan; dan penetapan kondisi dan syarat kerja. Sedangkan pelaksanaan perlindungan
Perindustrian dan Tenaga Kerja Kabupaten Bangkalan ada aplikasi yang dibuat oleh kementerian tenaga kerja bekerjasama dengan imigrasi. Jadi sebelum pihak imigrasi menerbitkan paspor bekerja maka harus mendapatkan rekomendasi dari Kabupaten Kota tempat calon pekerja migran Indonesia yang akan bekerja. Jadi kalau ingin membuat paspor harus ada rekomendasi dari Kabupaten setempat.

Dalam membuat rekomendasi tersebut, ada persyaratan bahwa pekerja migran Indonesia membawa identitas diri seperti KK dan KTP, kemudian ada surat izin dari keluarga, dan yang terpenting sudah ada surat perjanjian kerja antara calon pekerja migran Indonesia dengan perusahaan yang akan memperkerjakan yang berisi nama kedua belah pihak dan menyebutkan hak serta kewajiban masing-masing pihak. Jadi setelah ada syarat tersebut, kemudian Dinas Perindustrian dan Tenaga Kerja 
Kabupaten Bangkalan membuatkan form. Hal ini berfungsi supaya bisa mengetahui identitas pekerja migran Indonesia asal Kabupaten Bangkalan tersebut. Dari penjelasan diatas itu merupakan bentuk perlindungan sebelum bekerja yang diberikan Dinas Perindustrian dan Tenaga Kerja Kabupaten Bangkalan kepada calon pekerja migran Indonesia.

Perlindungan teknis menurut pasal 8 ayat (3) UU PPMI meliputi : a) Pemberian sosialisasi dan diseminasi informasi, b) Peningkatan kualitas calon pekerja migran Indonesia melalui pendidikan dan pelatihan kerja, c) Jaminan sosial, d) Fasilitasi pemenuhan hak calon pekerja migran Indonesia, e) Penguatan peran pegawai fungsional pengantar kerja, f) Pelayanan penempatan di layanan terpadu satu atap penempatan dan perlindungan pekerja migran Indonesia, g) Pembinaan dan pengawasan.

Sedangkan pelaksanaan perlindungan teknis sebelum pekerja migran Indonesia asal Kabupaten Bangkalan bekerja ke luar negeri yaitu
Dinas Perindustrian dan Tenaga Kerja Kabupaten Bangkalan melakukan penyuluhan kepada calon pekerja migran Indonesia asal Kabupaten Bangkalan. Penyuluhan disampaikan kepada masyarakat tentang bagaimana cara atau proses untuk bekerja ke luar negeri. Setelah itu membuat izin rekomendasi pembuatan paspor untuk bekerja.

Perlindungan sebelum bekerja yang dilaksanakan Dinas Perindustrian dan Tenaga Kerja Kabupaten Bangkalan belum sesuai dengan ketentuan pasal 8 ayat (3) UU PPMI dimana Dinas Perindustrian dan Tenaga Kerja Kabupaten Bangkalan hanya melakukan penyuluhan kepada masyarakat mengenai proses menjadi pekerja migran Indonesia tetapi belum melakukan penyuluhan mengenai bagaimana menjadi pekerja migran Indonesia yang baik agar tidak terjadi suatu masalah saat bekerja ke luar negeri dan juga Dinas Perindustrian dan Tenaga Kerja Kabupaten Bangkalan belum melakukan pendidikan dan pelatihan kerja kepada calon pekerja migran Indonesia asal 
Kabupaten Bangkalan yang bertujuan untuk meningkatkan kualitas calon pekerja migran Indonesia tersebut.

b) Perlindungan selama bekerja

Perlindungan selama bekerja merupakan perlindungan yang diberikan pemerintah pusat maupun pemerintah daerah kepada pekerja migran Indonesia yang sedang bekerja di luar negeri. Bentuk perlindungan selama bekerja yang diberikan oleh pemerintah Kabupaten Bangkalan kepada pekerja migran Indonesia asal Kabupaten Bangkalan yaitu sebenarnya Dinas tidak punya kewenangan dalam melindungi pekerja migran asal Bangkalan selama bekerja berdasarkan ketentuan pasal 41 huruf e dimana pemerintah daerah kabupaten/kota memiliki tugas dan tanggung jawab memberikan perlindungan pekerja migran Indonesia sebelum bekerja dan setelah bekerja di daerah kabupaten/kota yang menjadi tugas dan kewenangannya. Tetapi Dinas Perindustrian dan Tenaga Kerja Kabupaten Bangkalan berusaha mendapatkan informasi pekerja migran
Indonesia asal Kabupaten Bangkalan yang sedang bekerja ke luar negeri. ${ }^{1}$

Perlindungan selama bekerja sudah di tangani oleh P2TKI, P3TKI yang sudah punya kotak saran melalui internet. Jadi nantinya P2TKI, P3TKI yang akan menghubungi Dinas Perindustrian dan Tenaga Kerja Kabupaten Bangkalan terkait masalah dengan salah seorang pekerja migran Indonesia yang berdomisili di Kabupaten Bangkalan. Misalnya ada laporan dari P3TKI atas nama pekerja migran Indonesia asal Kabupaten Bangkalan, kemudian pihak Dinas Perindustrian dan Tenaga Kerja Kabupaten Bangkalan menelusuri terkait dengan identitas pekerja migran Indonesia apakah warga Kabupaten Bangkalan atau tidak. Dan jika memang benar warga Kabupaten Bangkalan, kemudian Dinas Perindustrian dan Tenaga Kerja

${ }^{1}$ Disarikan dari hasil wawancara bersama Ibu Hariyani Selaku Kepala Bidang Pelatihan Kerja dan Penempatan Tenaga Kerja Dinas Perindustrian dan Tenaga Kerja Kabupaten Bangkalan Tanggal 14 Januari 2018 
Kabupaten Bangkalan menghubungi keluarga pekerja migran tersebut.

Kemudian sebelum pekerja migran Indonesia berangkat ke luar negeri, Dinas Perindustrian dan Tenaga Kerja Kabupaten Bangkalan menanyakan apakah sudah ikut asuransi selama bekerja apa belum. Jika pekerja migran tersebut belum ikut asuransi maka di sarankan harus ikut tetapi kalau pekerja migran Indonesia berangkat melalui PT biasanya sudah include, di PT nya sudah di daftarkan asuransi. Dan jika pekerja migran Indonesia asal Kabupaten Bangkalan yang berangkat secara mandiri tetap di tanya apakah sudah ikut asuransi apa belum. Dinas sendiri tidak mungkin membawakan seorang pendamping untuk melindungi selama pekerja migran Indonesia bekerja di luar negeri. Jadi perlindungan selama bekerja yang diberikan Dinas Perindustrian dan Tenaga Kerja Kabupaten Bangkalan yaitu hanya berbentuk saran untuk mengikuti asuransi.

Perlindungan selama bekerja yang dilaksanakan oleh Dinas Perindustrian dan Tenaga Kerja Kabupaten Bangkalan jika dikaitkan dengan UU PPMI maka sudah sesuai dengan ketentuan pasal 41 huruf e bahwa Dinas Perindustrian dan Tenaga Kerja Kabupaten Bangkalan tidak berwenang memberikan perlindungan kepada pekerja migran Indonesia selama bekerja karena Dinas Perindustrian dan Tenaga Kerja Kabupaten Bangkalan hanya berkewajiban memberikan perlindungan kepada pekerja migran Indonesia asal Kabupaten Bangkalan hanya sebelum bekerja dan sesudah bekerja.

\section{c) Perlindungan sesudah bekerja}

Perlindungan sesudah bekerja merupakan perlindungan yang diberikan pemerintah pusat maupun pemerintah daerah kepada pekerja migran Indonesia yang sudah bekerja di luar negeri. Perlindungan sesudah bekerja diatur dalam pasal $24 \mathrm{UU}$ PPMI. Perlindungan sesudah bekerja menurut pasal 24 ayat (1) UU PPMI meliputi : 1) Fasilitasi kepulangan sampai daerah asal, 2) Penyelesaian hak pekerja migran Indonesia yang 
belum terpenuhi, 3) Fasilitasi di balai latihan kerja Dinas pengurusan pekerja migran Indonesia Perindustrian dan Tenaga Kerja yang sakit dan meninggal dunia, 4) Kabupaten Bangkalan seperti Rehabilitasi sosial dan reintegrasi sosial, 5) Pemberdayaan pekerja migran Indonesia dan keluarganya

Bentuk perlindungan sesudah bekerja yang diberikan oleh pemerintah Kabupaten Bangkalan kepada pekerja migran Indonesia asal Kabupaten Bangkalan yaitu Dinas Perindustrian dan Tenaga Kerja Kabupaten Bangkalan menanyakan apakah sudah pulang dari luar negeri apa belum. Setelah itu Dinas menanyakan apakah ingin kembali bekerja lagi menjadi pekerja migran atau tidak. Kalau ingin kembali bekerja ke luar negeri, Dinas Perindustrian dan Tenaga Kerja Kabupaten Bangkalan mengingatkan untuk berangkat secara legal dan mengikuti prosedurnya. Tetapi kalau pekerja migran tersebut tidak ingin berangkat lagi, Dinas Perindustrian dan Tenaga Kerja Kabupaten Bangkalan membantu atau menyuruh pekerja migran tersebut untuk mengikuti keterampilan-keterampilan keterampilan menjahit, komputer untuk umur yang masih muda, sedangkan kalau umurnya sudah tua bisa diikutkan keterampilan memasak dan kerajinan tangan.

Apabila dikaitkan dengan UU PPMI, maka pelaksanaan perlindungan pekerja migran Indonesia sesudah bekerja yang dilaksanakan oleh Dinas Perindustrian dan Tenaga Kerja Kabupaten Bangkalan belum sesuai dengan ketentuan pasal 24 ayat (1) UU PPMI dimana Dinas Perindutrian dan Tenaga Kerja Kabupaten Bangkalan belum memfasilitasi pekerja migran Indonesia yang pulang ke Indonesia dari bandara sampai dengan rumah pekerja migran Indonesia tetapi Dinas Perindustrian dan Tenaga Kerja Indonesia hanya memfasilitasi pekerja migran Indonesia yang sudah sampai rumah dengan cara mengikutsertakan pelatihan-pelatihan keterampilan bagi pekerja migran Indonesia asal Kabupaten Bangkalan yang tidak ingin kembali lagi. 
Dinas Perindustrian dan Tenaga Kerja belum memfasilitasi pengurusan pekerja migran Indonesia asal Kabupaten Bangkalan yang meninggal dunia saat bekerja di luar negeri. Pengurusan jenazah pekerja migran Indonesia asal Kabupaten Bangkalan dilakukan oleh pihak LP3TKI Surabaya. Pihak LP3TKI Surabaya mengurus jenazah pekerja migran tersebut dari bandara Surabaya sampai diantarkan ke kediaman keluarga pekerja migran di Kabupaten Bangkalan. Dan seharusnya Dinas Perindustrian dan Tenaga Kerja Kabupaten Bangkalan ikut mengantar pihak LP3TKI Surabaya kekediaman keluarga pekerja migran Indonesia yang meninggal dunia.

Permasalahan yang Timbul Dalam Proses Perlindungan Pekerja Migran

Dalam menjalankan perannya sebagai Dinas Perindustrian dan Tenaga Kerja Kabupaten Bangkalan dalam menangani perlindungan pekerja migran Indonesia asal Bangkalan harus mempunyai dokumen-dokumen pekerja migran Indonesia karena jika terjadi apa-apa yang dialami pekerja migran Indonesia di luar negeri, dinas perindustrian dan tenaga kerja kabupaten bangkalan bisa mengetahui identitas pekerja migran tersebut dan bisa menghubungi keluarga. Tetapi jika pekerja migran tersebut berangkat ke luar negeri segala ilegal, maka ini permasalahan yang timbul dalam melindungi pekerja migran Indonesia asal Bangkalan karena di dinas sendiri tidak ada dokumen apapun dan jika terjadi sesuatu dengan pekerja migran tersebut maka Dinas Perindustrian Dan Tenaga Kerja Kabupaten Bangkalan harus mencari alamat rumahnya. Karena di Dinas perindustrian dan Tenaga Kerja Kabupaten Bangkalan tidak punya catatan pasti.

Selain di Dinas Perindustrian dan Tenaga Kerja Kabupaten Bangkalan, Loka Pelayanan Penempatan dan Perlindungan Tenaga Kerja Indonesia (LP3TKI) Surabaya juga mengalami permasalahan dalam melindungi pekerja migran Indonesia seperti dari pekerja migran itu sendiri. Pekerja 
migran Indonesia tidak melapor kalau terjadi masalah tetapi yang melaporkan orang lain. Dan kadang juga dia membuat laporan tetapi waktu di suruh datang dia tidak datang, padahal dalam membuat laporan harus wawancara terlebih dulu terkait permasalahan apa yang di alami. Sehingga Loka Pelayanan Penempatan dan Perlindungan Tenaga Kerja Indonesia Surabaya bingung yang harus dilindungi itu apa karena tidak mengetahui tentang permasalahannya. Seperti kemarin ada orang dari Korea mengadu ke Loka Pelayanan Penempatan dan Perlindungan Tenaga Kerja Indonesia Surabaya, waktu disuruh datang tetapi dia tidak datang padahal dia harus tanda tangan surat aduan. $^{2}$

Upaya yang Dilakukan Pemerintah Kabupaten Bangkalan

2 Disarikan dari hasil wawancara bersama Bapak Makruf Selaku Kepala di Loka Pelayanan Penempatan dan Perlindungan Tenaga Kerja Indonesia (LP3TKI Surabaya) Tanggal 11 Januari 2018
Dalam pelaksanaan penempatan dan perlindungan PMI asal Bangkalan terdapat beberapa permasalahan yang dihadapi yaitu : (1) Deportasi dari negara penempatan, (2) meninggal dunia akibat kecelakaan kerja, (3) Menerima hukuman Pancung di Arab Saudi (4) meninggalkan anaknya di rumah sakit luar negeri dan (5) kebingungan di bandara Juanda Surabaya

Dengan adanya kasus-kasus yang menimpa pekerja migran Indonesia di luar negeri tentunya pemerintah Kabupaten Bangkalan melakukan upaya-upaya dalam melindungi pekerja migran Indonesia. Berikut merupakan realita upaya hukum yang dilakukan oleh pemerintah dalam melindungi pekerja migran Indonesia asal Kabupaten Bangkalan.

a) Pekerja migran Indonesia asal Bangkalan yang di deportasi dari negara penempatan

Banyaknya pekerja migran Indonesia asal Kabupaten Bangkalan yang dideportasi dari negara penempatan disebabkan karena banyaknya pekerja migran asal 
Kabupaten Bangkalan yang berangkat secara ilegal sehingga pekerja migran tersebut tidak terdaftar di Dinas Perindustrian dan Tenaga Kerja Kabupaten Bangkalan dan pekerja migran Indonesia tersebut akan di deportasi dari negara penempatan karena tidak memiliki dokumen lengkap.

Proses penanganan yang dilakukan jika terjadi pemulangan pekerja migran Indonesia asal Kabupaten Bangkalan ke negara penempatan yaitu Dinas Perindustrian dan Tenaga Kerja Kabupaten Bangkalan hanya bisa mencegah supaya tidak terjadi pekerja migran Indonesia yang berangkat secara ilegal dengan cara memberikan gambaran kepada calon pekerja migran Indonesia asal Kabupaten Bangkalan tentang akibat jika berangkat menjadi pekerja migran Indonesia secara ilegal, misalnya tidak ada yang melindungi jika berangkat ke luar negeri secara ilegal dan bisa dipenjara kalau ketangkap. Dan Dinas Perindustrian dan Tenaga Kerja Kabupaten Bangkalan tidak ingin tau jika terjadi masalah yang dialami pekerja migran Indonesia ilegal asal Kabupaten Bangkalan, seperti adanya deportasi dari negara penempatan. ${ }^{3}$

Sedangkan penanganan yang dilakukan oleh LP3TKI Surabaya yaitu pihak LP3TKI Surabaya sendiri tidak mengetahui secara pasti jumlah pekerja migran Indonesia asal Kabupaten Bangkalan yang ilegal karena data-data pekerja migran tersebut tidak ada karena mereka berangkat ke luar negeri secara non prosedur. Tetapi jika terjadi pekerja migran Indonesia yang ilegal asal Kabupaten Bangkalan yang di deportasi dari negara penempatan maka kemudian LP3TKI Surabaya memfasilitasi kepulangan pekerja migran tersebut dengan memberikan uang transportasi kepada pekerja migran tersebut untuk digunakan pulang ke daerah asalnya. ${ }^{4}$

3 Disarikan dari hasil wawancara bersama Ibu Hariyani Selaku Kepala Bidang Pelatihan Kerja dan Penempatan Tenaga Kerja Dinas Perindustrian dan Tenaga Kerja Kabupaten Bangkalan Tanggal 14 Januari 2018

4 Disarikan dari hasil wawancara bersama Bapak Eko di Loka Pelayanan Penempatan dan Perlindungan Tenaga Kerja 
Agar tidak terjadi deportasi pekerja migran Indonesia, seharusnya Dinas Perindustrian dan Tenaga Kerja Kabupaten Bangkalan lebih memperhatikan pekerja migran yang mengalami deportasi yaitu dengan cara membantu kepulangannya dan melakukan sosialisasi kepada pekerja migran yang di deportasi tersebut agar tidak lagi berangkat bekerja ke luar negeri secara ilegal. Selain itu, Dinas Perindustrian dan Tenaga Kerja Kabupaten Bangkalan seharusnya merekap data-data mengenai pekerja migran Indonesia asal Bangkalan yang di deportasi dari negara penempatan. Karena di Dinas Perindustrian dan Tenaga Kerja kabupaten Bangkalan sendiri tidak adanya data-data pekerja migran yang di deportasi karena Dinas Perindustrian dan Tenaga Kerja Kabupaten Bangkalan beranggapan bahwa pekerja migran Indonesia yang berangkat secara ilegal itu segala akibatnya di tanggung oleh pekerja migran itu sendiri.

Indonesia (LP3TKI Surabaya) Tanggal 4 Februari 2018 b) Pekerja Migran Indonesia asal Kabupaten Bangkalan meninggal dunia akibat kecelakaan kerja

Proses penanganan jika ada pekerja migran Indonesia asal Kabupaten Bangkalan yang meninggal dunia di luar negeri yaitu LP3TKI Surabaya mendapatkan Brifek atau surat keterangan dari KBRI di negara penempatan yang isinya yaitu pemberitahuan jika ada pekerja migran Indonesia asal Kabupaten Bangkalan yang meninggal dunia di negara penempatan. Setelah itu pihak LP3TKI Surabaya menghubungi pihak P4TKI Pamekasan untuk memastikan alamat pekerja migran tersebut memang benar masyarakat Kabupaten Bangkalan atau tidak. Dan jika memang benar warga Kabupaten Bangkalan kemudian pihak LP3TKI Surabaya mengirim pemberitahuan ke KBRI negara penempatan. Setelah itu jenazah pekerja migran tersebut dikirimkan ke keluarganya oleh pihak LP3TKI Surabaya bersama pihak P4TKI Pamekasan. 
Proses penanganan tersebut seharusnya juga dilakukan oleh Dinas Perindustrian dan Tenaga Kerja Kabupaten Bangkalan karena dalam pasal 24 ayat (1) disebutkan bahwa Dinas Perindustrian dan Tenaga Kerja Kabupaten Bangkalan bertanggung jawab mengurus kepulangan pekerja migran Indonesia yang meninggal dunia seperti memastikan alamat pekerja migran Indonesia tersebut apa benar warga Kabupaten Bangkalan atau tidak. Tetapi faktanya, Dinas Perindustrian dan Tenaga Kerja Kabupaten Bangkalan sendiri tidak selalu membantu memastikan alamat pekerja migran Indonesia asal Kabupaten Bangkalan. Dan yang memastikan alamat pekerja migran tersebut dilakukan oleh LP3TKI Surabaya dengan dibantu oleh P4TKI Pamekasan.

Proses yang dilakukan dalam menangani kasus tersebut lebih aktif dilakukan oleh pihak LP3TKI Surabaya bersama dengan pihak P4TKI Pamekasan, sedangkan Dinas Perindustrian dan Tenaga Kerja Kabupaten Bangkalan sendiri kadang- kadang juga membantu menelusuri alamat pekerja migran Indonesia asal Kabupaten Bangkalan yang terkena kasus dan jika ada pekerja migran Indonesia asal Kabupaten Bangkalan yang meninggal di luar negeri maka Dinas Perindustrian dan Tenaga Kerja Kabupaten Bangkalan hanya menunggu kepulangan jenazah di rumah kediaman pekerja migran tersebut.

\section{c) Pekerja migran Indonesia yang meninggalkan anaknya di rumah sakit luar negeri}

Setelah pihak LP3TKI Surabaya mendapatkan informasi dari KJRI Penang, Malaysia bahwa ada kasus pekerja migran Indonesia yang mengaku berasal dari Kabupaten Bangkalan yang meninggalkan anaknya di rumah sakit karena tidak sanggup membayar biaya rumah sakitnya. Kemudian pihak LP3TKI menelusuri alamat pekerja migran Indonesia tersebut di Kabupaten Bangkalan dengan dibantu oleh P4TKI Pamekasan, tetapi hasil penelusuran alamat yang dilakukan oleh LP3TKI Surabaya dengan dibantu oleh P4TKI 
Pamekasan tidak ada warga Kabupaten Bangkalan yang bernama pekerja migran tersebut dan akhirnya LP3TKI Surabaya menyampaikan informasinya tersebut ke KBRI Penempatan.

Dinas Perindustrian dan Tenaga Kerja Kabupaten Bangkalan seharusnya juga membantu P4TKI Pamekasan dalam melakukan penelusuran alamat rumah pekerja migran tersebut. Namun, faktanya penelusuran alamat rumah pekerja migran tersebut hanya dilakukan oleh P4TKI Pamekasan.

\section{d) Pekerja migran Indonesia asal Kabupaten Bangkalan yang kebingungan di bandara Juanda} Surabaya

Kasus yang menimpa pekerja migran Indonesia yang sedang kebingungan di bandara dikarenakan kehabisan uang untuk pulang ke rumahnya. Setelah pihak LP3TKI Surabaya mendapatkan informasi dari Deputi Perlindungan bahwa ada pekerja migran Indonesia asal Kabupaten Bangkalan yang sedang kebingungan di bandara Juanda Surabaya dari kehabisan uang setelah pulang dari luar negeri, maka kemudian pihak LP3TKI Surabaya membantu membiayai kepulangan pekerja migran Indonesia tersebut dengan memberikan uang untuk perjalanannya pulang kerumah.

Proses yang dilakukan dalam menangani kasus tersebut lebih aktif dilakukan oleh pihak LP3TKI Surabaya, sedangkan Dinas Perindustrian dan Tenaga Kerja Kabupaten Bangkalan sendiri tidak mengetahui jika ada pekerja migran Indonesia asal Kabupaten Bangkalan yang mengalami kebingungan di Bandara Juanda Surabaya karena kehabisan uang untuk biaya pulang ke Bangkalan.

Seharusnya Dinas Perindustrian dan Tenaga Kerja Kabupaten Bangkalan bertanggung jawab mengurus kepulangan sampai daerah asal pekerja migran Indonesia asal Kabupaten Bangkalan. Karena dalam pasal 24 ayat (1) sudah disebutkan bahwa Dinas Perindustrian dan Tenaga Kerja Kabupaten Bangkalan bertanggung jawab mengurus kepulangan pekerja migran Indonesia 
asal Kabupaten Bangkalan sampai daerah asalnya. Sehingga tidak ada lagi pekerja migran Indonesia asal Kabupaten Bangkalan yang kebingungan di bandara karena kehabisan uang untuk pulang ke daerah asalnya.

\section{e) Penanganan kasus hukuman mati Pekerja Migran Indonesia asal Kabupaten Bangkalan}

1) Kasus Siti Zaenab yang dihukum pancung di Arab Saudi

Upaya yang dilakukan keluarga Siti Zaenab yaitu dengan cara datang ke Jakarta bersama Ibu Khofifah untuk bertemu bapak presiden Susilo Bambang Yudhoyono supaya membebaskan anggota keluarganya dan pihak keluarga berangkat ke luar negeri untuk menemui keluarga majikannya agar mendapatkan maaf dan anggota keluarganya bisa dibebaskan. Namun pada akhirnya proses itu tidak mendapatkan hasil yang positif. Maka pada akhirnya Siti Zaenab tetap mengalami hukuman pancung.

\section{2) Kasus Zaini Misrin yang dihukum pancung di Arab Saudi}

Upaya yang dilakukan keluarga Zaini Misrin yaitu anak pertama dari Zaini Misrin mengirimkan email kepada Kementerian Luar Negeri agar bisa membebaskan Zaini Misrin dari hukuman mati dan akhirnya anak Zaini Misrin diajak ke Arab Saudi bersama Ibu Menteri Luar negeri untuk menemui anak dari majikannya agar mendapatkan maaf supaya Zaini Misrin bisa bebas tetapi anak dari majikannya tidak mau menemui keluarga dari Zaini Misrin.

Dengan adanya kasus tersebut tentunya pemerintah daerah Kabupaten/kota Bangkalan melakukan upaya dalam menangani kasus tersebut. Karena didalam UU PPMI sendiri sudah dijelaskan mengenai tugas dan tanggung jawab pemerintah daerah Kabupaten/Kota dalam melindungi pekerja migran Indonesia sebagaimana terdapat didalam pasal 41 UU PPMI dan yang melakukan upaya hukum terhadap pekerja migran Indonesia di Daerah Kabupaten 
Bangkalan dilakukan oleh Dinas

Perindustrian dan Tenaga Kerja

Kabupaten Bangkalan.

Upaya hukum yang dilakukan Dinas Perindustrian dan Tenaga Kerja Kabupaten Bangkalan yaitu Dinas Perindustrian dan Tenaga Kerja Kabupaten Bangkalan sendiri bekerja sama dengan P2TKI, P3TKI. Jadi badan-badan itulah yang nantinya lebih intens untuk melakukan upayaupaya perlindungan. Sedangkan Dinas Perindustrian dan Tenaga Kerja Kabupaten Bangkalan memiliki kewajiban untuk membuktikan bahwa pekerja migran Indonesia tersebut memang warga dari Kabupaten Bangkalan, dan jika benar maka kemudian Dinas Perindustrian dan Tenaga Kerja Kabupaten Bangkalan menghubungi keluarga pekerja migran tersebut. Seperti kasus Siti Zaenab itu memang warga Bangkalan, kemudian izin rekomendasinya ada, setelah itu Dinas Perindustrian dan Tenaga Kerja Kabupaten Bangkalan menghubungi keluarganya bahwa Siti Zaenab sedang terkena kasus.
Jadi Dinas Perindustrian dan Tenaga Kerja Kabupaten Bangkalan tidak punya kewenangan untuk melakukan upaya-upaya hukum, tetapi upayanya hanya menunjukkan berupa dokumen-dokumen kalau pekerja migran Indonesia yang bersangkutan memang dari Kabupaten Bangkalan, dan berkewajiban menghubungi keluarganya serta sebagai fasilitator antara keluarganya dengan P3TKI.

Upaya hukum yang dilakukan Dinas Perindustrian dan Tenaga Kerja Kabupaten Bangkalan jika dikaitkan dengan Pasal 41 huruf e UU PPMI maka upaya hukum yang dilakukan Dinas Perindustrian dan Tenaga Kerja Kabupaten Bangkalan sudah sesuai dengan tugas dan tanggung jawabnya karena tidak berwenang melindungi pekerja migran Indonesia selama bekerja. Namun Seharusnya Dinas Perindustrian dan Tenaga Kerja Kabupaten Bangkalan ikut membantu keluarga korban pekerja migran Indonesia yang terkena kasus hukuman mati di Arab Saudi yaitu dengan cara membantu melakukan upaya-upaya untuk disampaikan kepada pemerintah 
provinsi dan nantinya pemerintah provinsi menyampaikannya ke pemerintah pusat supaya hukuman mati yang terjadi pada pekerja migran Indonesia asal Kabupaten Bangkalan tidak terjadi.

\section{Tetapi faktanya, Dinas}

Perindustrian dan Tenaga Kerja

Kabupaten Bangkalan tidak

melakukan upaya-upaya untuk membebaskan pekerja migran asal Kabupaten Bangkalan yang dihukum pancung di Arab Saudi yaitu Siti Zaenab dan Zaini Misrin. Pihak keluarga dari Siti Zaenab dan Zaini Misrin yang melakukan upaya sendiri untuk membebaskan anggota keluarganya.

Seharusnya Dinas Perindustrian dan Tenaga kerja harus bisa mencegah agar tidak terjadi kasus hukuman mati yang menimpa pekerja migran Indonesia asal kabupaten Bangkalan dengan cara memberikan pengarahan agar selama bekerja di luar negeri harus lebih hati-hati dan jika terjadi permasalahan sebaiknya melapor ke perwakilan Indonesia yang ada di luar negeri. Dan Dinas Perindustrian dan
Tenaga Kerja Kabupaten Bangkalan harus lebih mendesak pemerintah Bangkalan supaya Peraturan Daerah yang mengatur perlindungan pekerja migran Indonesia asal Kabupaten Bangkalan untuk segera disahkan karena di Kabupaten Bangkalan sendiri sudah terdapat 2 pekerja migran Indonesia yang dihukum mati di Arab Saudi.

Di Kabupaten Bangkalan sendiri tidak adanya data secara lebih rinci mengenai permasalahan yang menimpa pekerja migran Indonesia asal Kabupaten Bangkalan selama tahun 2018. Dan seharusnya Dinas Perindustrian dan Tenaga Kerja Kabupaten Bangkalan membuat datadata mengenai pekerja migran Indonesia asal Kabupaten Bangkalan karena itu sudah merupakan tugas dan tanggung jawabnya sebagaimana yang sudah diatur dalam pasal 41 huruf $b$ UU PPMI.

Tidak hanya pemerintah daerah Kabupaten yang memiliki kewajiban melindungi pekerja migran Indonesia namun pemerintah daerah Provinsi juga berkewajiban melindungi pekerja 
migran tersebut. Karena dalam UU PPMI sudah disebutkan bahwa pemerintah daerah Provinsi memiliki tugas dan tanggung jawab dalam melindungi pekerja migran Indonesia yang sebagaimana diatur dalam pasal 40 UU PPMI.

Pemerintah daerah Provinsi dalam melindungi pekerja migran Indonesia dilaksanakan oleh Loka Pelayanan Penempatan dan Perlindungan Tenaga Kerja Indonesia (LP3TKI) Surabaya. LP3TKI Surabaya dalam melakukan upaya hukum terhadap pekerja migran Indonesia asal Kabupaten Bangkalan yaitu LP3TKI tidak bisa melakukan upaya hukum, karena cuma negara yang bisa melakukan upaya hukum. LP3TKI hanya sekedar memberikan masukan ke BNP pusat agar tidak terjadi hukuman mati. Karena di Arab Saudi itu siapapun tidak akan bisa melindungi pekerja migran Indonesia kecuali keluarga orang yang dibunuh. Karena disana hutang nyawa harus dibayar dengan nyawa dan Ibu Siti Zaenab sama Zaini Misrin dihukum pancung di Arab karena keluarga korban tidak menghendaki untuk dibebaskan dan kerajaan saja tidak bisa intervensi warganya. Inilah perbedaan undang-undang antar negara dan undang-undang Indonesia disana tidak berlaku dan di Arab Saudi ada undang-undang tersendiri yang mana disebutkan jika ada seseorang yang mencuri maka tangannya harus dipotong dan yang bisa menyelamatkan cuma orang yang dimaling. Jadi kita tetap berusaha tapi keputusan tetap dikeluarga atau korban.

Upaya hukum yang dilakukan LP3TKI Surabaya jika dikaitkan dengan Pasal 40 huruf e UU PPMI maka sudah sesuai karena LP3TKI Surabaya tidak punya kewenangan melakukan perlindungan selama bekerja. Namun, LP3TKI Surabaya berusaha memberikan masukan ke pemerintah pusat supaya hukuman mati yang menimpa pekerja migran Indonesia asal Kabupaten Bangkalan tidak terjadi lagi.

\section{Simpulan}

Simpulan yang dapat diambil dalam penulisan ini adalah : 
1) Pelaksanaan perlindungan pekerja migran Indonesia asal Kabupaten Bangkalan yang dilaksanakan oleh Dinas Perindustrian dan Tenaga Kerja Kabupaten Bangkalan meliputi perlindungan sebelum bekerja yaitu melakukan penyuluhan. Penyuluhan disampaikan kepada masyarakat tentang bagaimana cara atau proses untuk bekerja ke luar negeri dan setelah itu membuat izin rekomendasi pembuatan paspor untuk bekerja. Perlindungan selama bekerja yaitu tidak adanya kewenangan untuk melakukan perlindungan selama bekerja tetapi Dinas Perindustrian dan tenaga Kerja Kabupaten Bangkalan berusaha mendapatkan informasi tentang pekerja migran Indonesia di luar negeri. Perlindungan sesudah bekerja yaitu memfasilitasi setelah kepulangan pekerja migran Indonesia asal Kabupaten Bangkalan yaitu menanyakan apakah sudah pulang atau belum dan mengikutkan pelatihan- pelatihan bagi pekerja migran Indonesia yang tidak ingin kembali lagi bekerja ke luar negeri.

2) Penanganan hukum yang dilakukan Dinas Perindustrian dan Tenaga Kerja Kabupaten Bangkalan terhadap kasus pekerja migran yang dideportasi yaitu melakukan pencegahan agar pekerja migran tidak berangkat secara nonprosedural, kasus pekerja migran yang meninggal dunia akibat kecelakaan kerja yaitu, pekerja migran yang meninggalkan anaknya dirumah sakit, kasus pekerja migran yang kebingungan di Bandara Juanda kesemua penanganan kasus tersebut lebih aktif dilakukan oleh LP3TKI Surabaya, dalam hal ini Dinas Perindustrian dan Tenaga Kerja Kabupaten Bangkalan melakukan upaya berupa koordinasi dengan instansi terkait. Untuk kasus pekerja migran yang dihukum pancung di Arab Saudi pihak keluarga lebih aktif berperan, sedangkan Dinas 
Perindustrian dan Tenaga Kerja Kabupaten Bangkalan hanya memastikan alamat pekerja migran dan sebagai fasilitator antara keluarga pekerja migran dengan LP3TKI Surabaya.

\section{Ucapan Terima Kasih}

Penelitian ini didanai oleh LPPM Universitas Trunojoyo Madura.

\section{Daftar Pustaka}

\section{Buku}

Joni, S, Bambang, 2013, Hukum Ketenagakerjaan, Bandung: CV Pustaka Setia.

Hanitijo Soemitro, Ronny. 1998, Metodelogi Penelitian Hukum Dan Jurimetri, Jakarta: Ghalia Indonesia.

Harianto, Aries, 2016, Hukum Ketenagakerjaan Makna Kesusilaan Dalam Perjanjian Kerja, Yogyakarta, LaksBang PRESSindo.

Husni, Lalu, 2012, Pengantar Hukum Ketenagakerjaan Indonesia, Jakarta: PT Rajagrafindo Persada.

Irsan, Koesparmono dan Armansyah, 2016) , Hukum Tenaga Kerja
Suatu Pengantar, Jakarta: Erlangga.

Johan Nasution, Bahder, 2016, Metode Penelitian Ilmu Hukum, Bandung, Mandar Maju.

Muslan. Abdurrahman, 2006, Ketidakpatuhan TKI, Malang: UMM Press.

Rachmat, Suliati, 2007, Beberapa Perlindungan Hukum Khusus Bagi Buruh Wanita, Jakarta. Joni

\section{Jurnal}

Ardhanariswari, Riris, 2017, "Peran Desa Sebagai Basis Migrasi Aman Dalam Perlindungan Tenaga Kerja Indonesia", Pena Justisia Media Komunikasi dan kajian Hukum, Vol 17, No 1)

Listiani, Tri, 2012, "Kendala perlindungan Hukum Buruh Migran di Kabupaten Cilacap", Dianmika Hukum, Vol 12, No 2.

Natalis, Aga, 2018, "Politik Hukum Perlindungan Pekerja Migran Perempuan di Indonesia", Pandecta, Vol 13, No 2, Desember.

Nofita, Dwi, 2019, "Peranan Pemerintah Daerah Dalam Upaya Perlindungan Pra penempatan Pekerja Migran Indonesua di Luar Negeri (Studi di Dinas Perindustrian dan Tenaga Kerja Kabupaten Purworejo", Diponegoro Law Journal, Vol 8, No 3. 
Noor \& Shaker, 2017, "Perceived Workplace Discrimination, Coping and Psycological Distress among Unskilled Indonesian Migrant Workers in Malaysia, International Journal of Intercultural Relations, vol 57.

Rahayu, Devi, 2020, "State Responsibility in Fulfilling The Rights of Indonesian Migrant Workers Durung Pandemic Era", Advances in Social Science, Education and Humanities Research, Vol 473, ICSS.

Ramdlany, Agus, A., 2016, "Studi Moratorium Sebagai Upaya Perlindungan Pengiriman TKI Berdasarkan UU No 39 Tahun 2004”, Rechtidee, Vol 11, No 2, Desember.

Rizky, 2018, "Politik Hukum Perlindungan TKI Purna Fase Bekerja", Kanun Jurnal Ilmu Hukum, Vol 20, No 1.

Widiyahseno, Bambang, 2018, "Paradigma Baru Model Perlindungan Pekerja Migran Indonesia Dalam perspektif Undang-undang RI No 18 Tahun 2017" , Socio Informa, Vol 4, No 3, September-Desember.

Wulan, Retno, Tyas, 2017, "Perlindungan Buruh Migran dari Hulu ke Hilir Melalui Desa Peduli Buruh Migran (Desbumi) Studi Di Desa Kahuripan Wonosobo Jawa Tengah dan
DEsa Nyerot Lombok Tengah NTB”, Sodality Jurnal sosiologi Pedesaan, Vol 5, No 2.

\section{Website}

Bank Indonesia dan BNP2TKI, "Jumlah Tenaga Kerja Indonesia (TKI) Menurut Negara Penempatan (Ribuan Orang)", dari

https://www.bi.go.id/seki/tabel/T ABEL5 30.pdf diakses pada 11 september 2018 pukul 11.26 WIB.

Badan Nasional Penempatan dan Perlindungan Tenaga Kerja Indonesia (BNP2TKI), "Jumlah Pekerja Migran Indonesia (PMI) Januari-April 2018", dari http://lokadata.beritagar.id/chart/ preview/jumlah-pekerja-migranindonesia-pmi diakses pada tanggal 23 September 2018 pukul 07.41 WIB.

Petriella, Yanita, 2018. "Jumlah Winsus yang ke Luar Negeri Bakal Tumbuh 10\% Tahun ini”, 19 Juli 2018, dari http://industri.bisnis.com/read/20 $\underline{180719 / 12 / 818390 / \text { jumlah- }}$ wisnus-yang-ke-luar-negeribakal-tumbuh-10-tahun-ini diakses pada tanggal 01 Oktober 2018 pukul 21.09 WIB.

Wahyudi, Ridwan, "Mengenal TeoriTeori Migrasi Pekerja Internasional", 18 Agustus 2015, dari

https://buruhmigran.or.id/2015/0 8/18/mengenal-teori-teori- 
migrasi-pekerja-internasional/,

diakses pada tanggal 30

September 2018 pukul 20.34

$\underline{\text { WIB }}$ 